
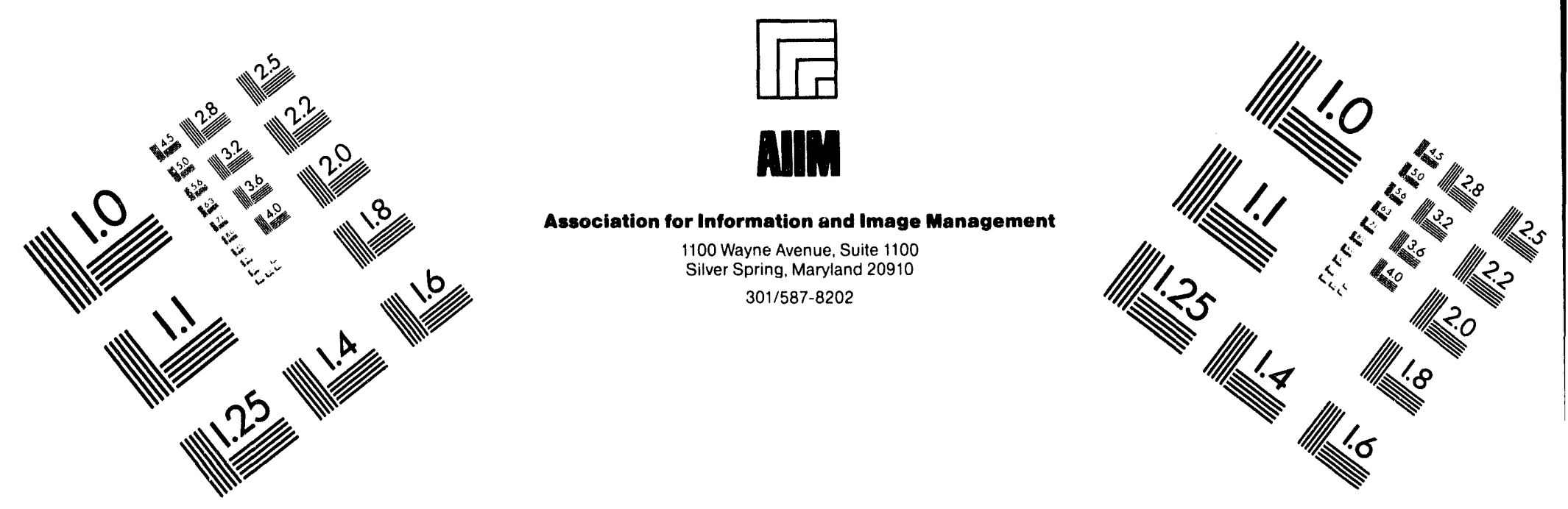

Centimeter

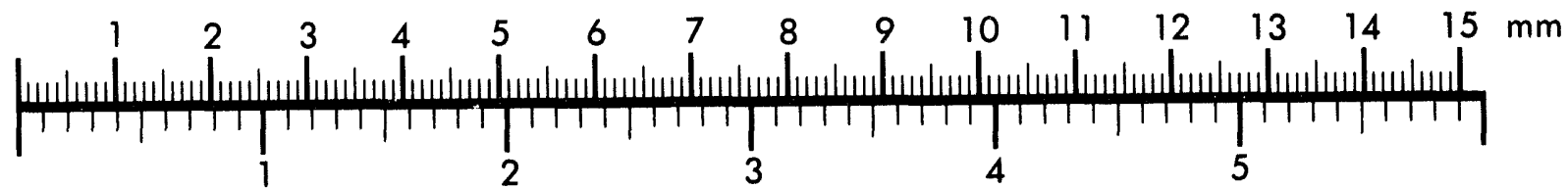

Inches
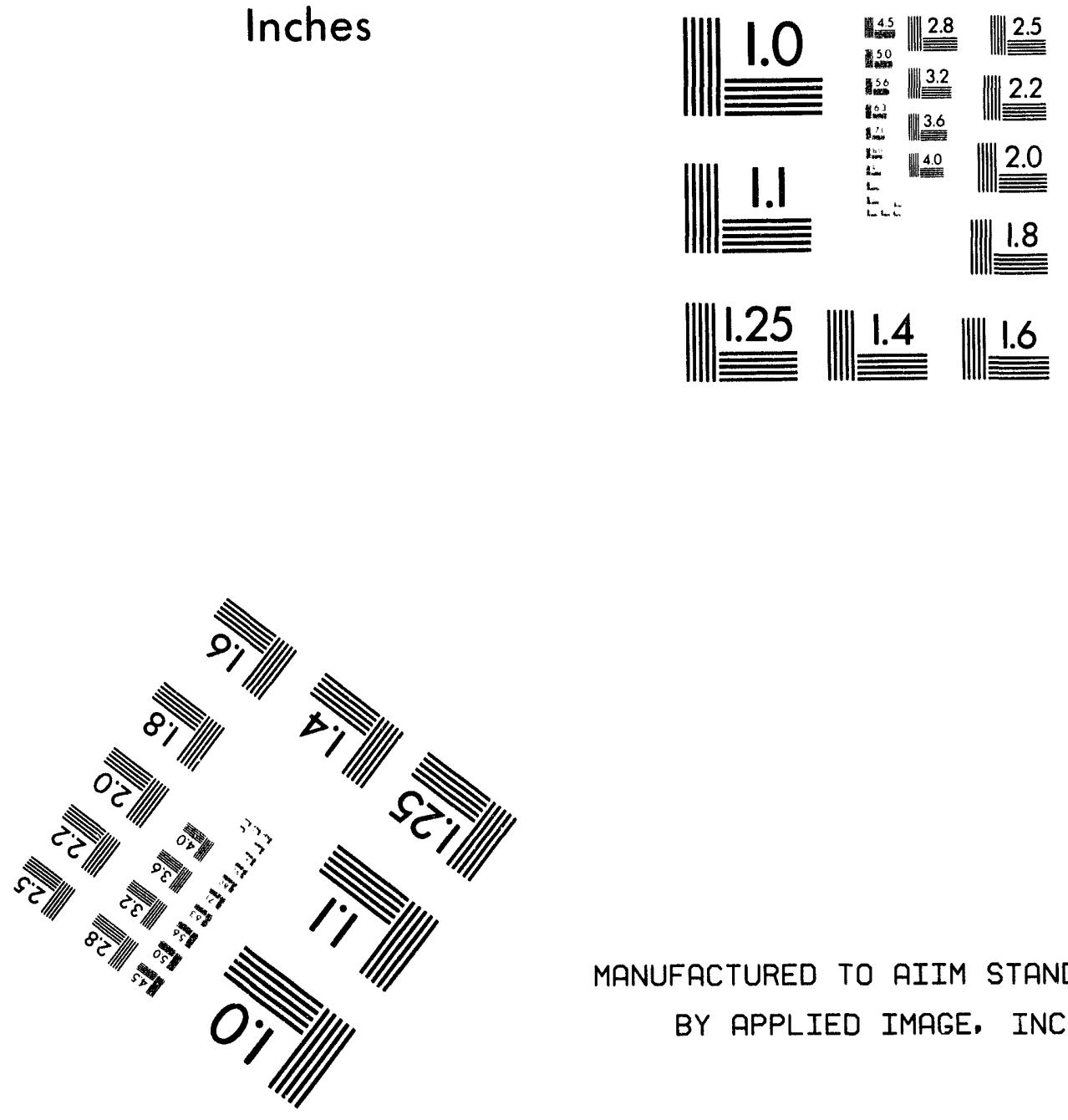

MANUFACTURED TO AIIM STANDARDS

BY APPLIED IMAGE, INC.

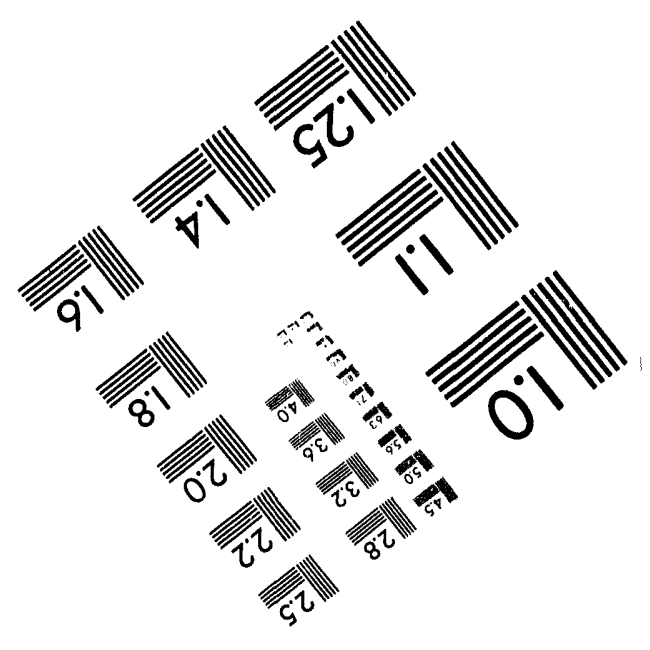



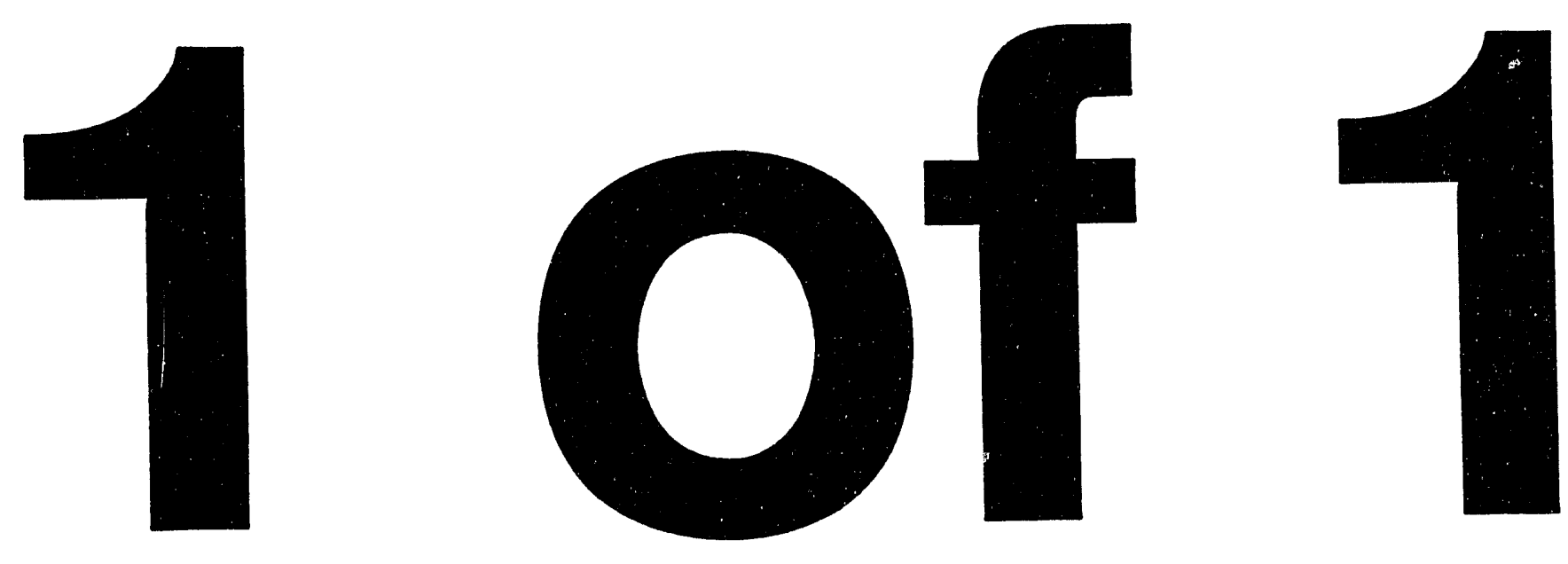


\title{
Corf $-940630^{-}-36$
}

UCRL-JC-117395

PREPRINT

\section{Use of the National Ignition Facility for the Develcpment of Inertial Fusion Energy}

\author{
M. Tobin, \\ G. Logan,
}

A. Anderson,

T. De LaRubia Diaz

This paper was prepared for submittal to the

American Nuclear Society

11th Topical Meeting on the Technology of Fusion Energy

New Orleans, Louisiana

June 19-23, 1994

\section{June 1994}

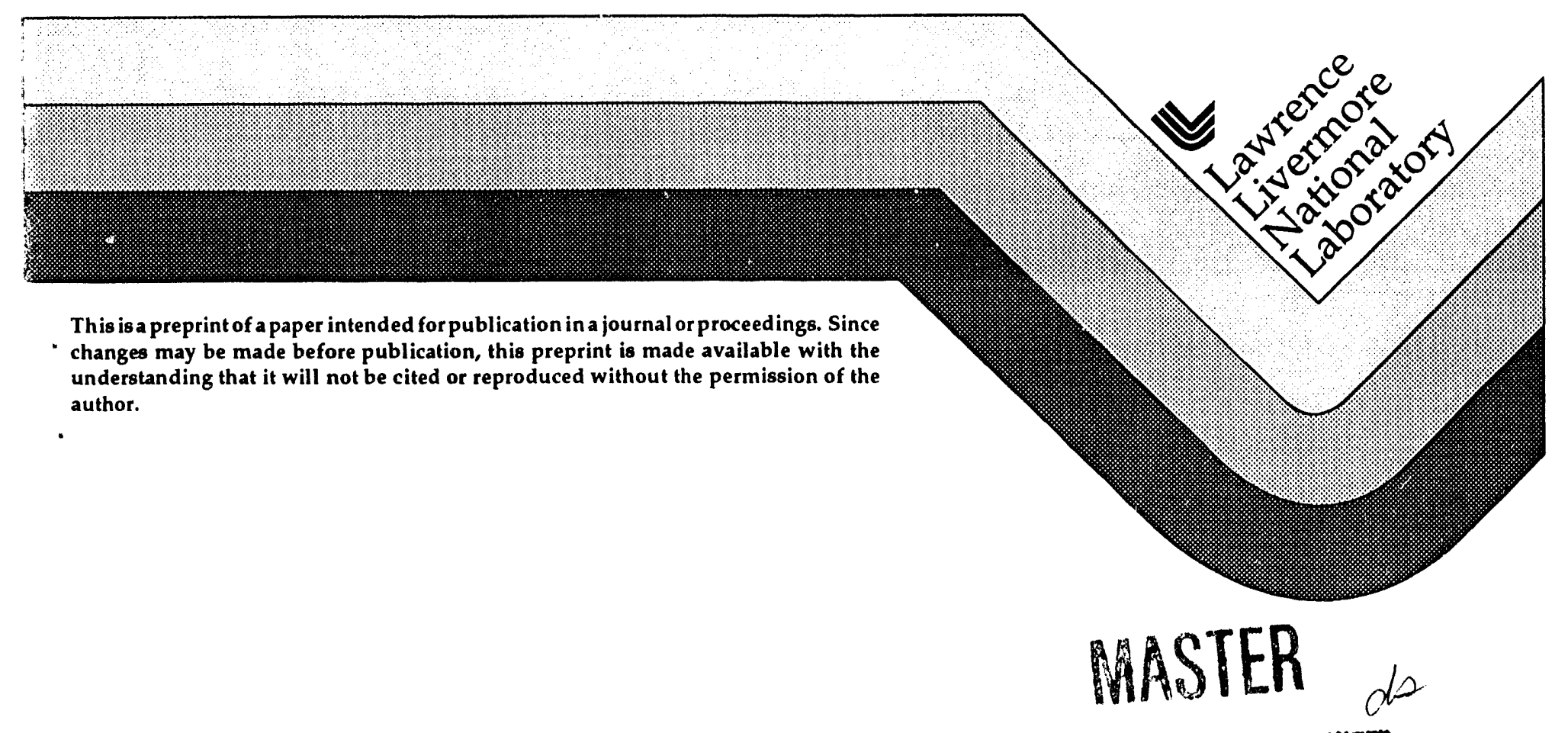

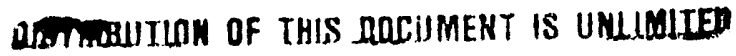




\section{DISCLAIMER}

This document was prepared as an account of work sponsored by an agency of the United States Government. Neither the United States Government nor the University of California nor any of their employees, makes any warranty, express or implied, or assumes any legal liability or responsibility for the accuracy, completeness, or usefulness of any information, apparatus, product, or process disclosed, or represents that its use would not infringe privately owned rights. Reference herein to any specific conmercial products, process, or service by trade name, trademark, manufacturer, or oherwise, does nol necessarily constitute or imply its endorsement, recommendation, or favoring by the United States Government or the University of California. The views and opinions of authors expressed herein do not necessarily state or reflect those of the United States Government thereof, and shall not be used for advertising or product endorsement purposes. 


\title{
USE OF THE NATIONAL IGNITION FACILITY FOR THE DEVELOPMENT OF INERTTAL FUSION ENERGY
}

\author{
M. Tobin, G. Logan, A. Anderson, \\ T. De LaRubia Diaz \\ University of Califomia \\ Lawrence Livermore National Laboratory \\ P.O. Box 808 \\ Livermore, CA 94551 \\ (510) $423-1168$
}

\begin{abstract}
The authors are greatly indebted to many others for much of the information in this paper, significantly drawn from the report (in progress) of the NIF for IFE Workshop, and thereby acknowleges contributions by K. Schultz-General Atomics, V. Schrock-UC Berkeley, W. Meier-W.J. Schafer Assoc, M. Abdou- UCLA, R. Bangerter-LBL, R. Tokheim-SRI, Intl, and all of the Workshop attendees.
\end{abstract}

\section{INIRODUCTION}

The Department of Energy is currently considering establishing the National Ignition Facility [NIF] as a formal project. The scientific goal of the facility is to achieve, for the first time in the laboratory, the ignition of an inertial confinement fusion target. The laser which will drive the target to ignition will deliver 1.8 MJ of $0.35 \mathrm{~mm}$ light, in a shaped $20 \mathrm{~ns}$ pulse, into a $\sim 1$ $\mathrm{cm}$ long, $0.6 \mathrm{~cm}$ diameter cryogenic holhraum, creating $x$ rays to compress the $-1 \mathrm{~mm}$ capsule containing $0.2 \mathrm{mg}$ of deuterium and tritium. [see National Ignition Facility Design, Schedule, and Cost, J. Paisner, et al, this publication] While ignition is indicated by fusion yields of $\sim 10$ 's of $\mathrm{kJ}$, yields of up to $20 \mathrm{MJ}$ appear possible, and will be contained in a 5-m radius aluminum chamber.

The realization of ignition in the laboratory, and the capabilities of the NIF itself, will make major contributions to several areas of major national importance: science-based nuclear weapon stockpile stewardship, high energy density science, inertial fusion energy [IFE], and complementary nuclear weapons effects testing. Here we discuss the contributions of NIF to IFE, specifically incorporating the results of the Workshop on the Use of NIF for IFE, hosted by the University of California, Berkeley, [Virgil Schrock, Department of Nuclear Engineering] from February 22-24, 1994.

The primary purpose of the workshop was to gather input from the inertial confinement fusion (ICF) laboratories, private industry, and universities on the potential use of the NIF to conduct experiments in support of the development of IFE. To accomplish this, we asked the over 60 workshop participants to identify key credibility and development issues for IFE in four areas [session chairmen]:
Target Physics [Roger Bangerter, '̄BL] - Issues related to the design and performance of targets for IFE

Chamber Dynamics [Robert Tokheim, SRI] - Issues in IFE chambers resulting from the deposition of $x$ rays and debris

Inertial Fusion Power Technology [Mohammed Abdou, UCLA] - Issues for energy conversion, tritum breeding and processing, and radiation shielding; interactions of neutrons with materials; and chamber design

Target Systems [Ken Schultz, General Atomics] Issues related to automated, high-production-rate manufacture of low-cost targets for IFE, target handling and transport, target injection, tracking, and beam pointing.

For the issues identified in these areas, particpants considered what experiments could be conducted using the NIF to address or even resolve these issues. Particpants identified what developments (e.g., in diagnostics, predictive capabilites, etc.) would be needed in parallel with NIF development, construction, and operations, to support full utilization of the NIF for such experiments. Participants were encouraged to suggest any improvements to the NIF design that would improve its capabilty to perform the proposed experiments.

We recognize, since IFE is not sufficiently developed, that it is premature to suggest the features best surted for electrical power plants based on the inertial fusion process. However, in order to efficiently facilitate discussions of details of specific potential NIF experiments in the limited time, we constrained the scope of the workshop. We primarily considered the issues for IFE power plants that would use a heavy ion driver and indirect drive targets, have repetition rates of 1 to $10 \mathrm{~Hz}$, yields of 100 to $500 \mathrm{MJ}$, and employ a inner blanket to provide first wall structural protection, breed tritium, and remove heat. 
The role of NIF for IFE development was considered in the context of a possible IFE development plan. The demonstration of heavy ion inertial fusion energy requires several facilities. While some important 'precursor' experiments may be possible on current facilities such as Nova and soon Omega Upgrade, the National Ignition Facility demonstrating target ignition and gain, is the first major IFE facility. In parallel with NIF, both the Induction Linac Systems Experiment (ILSE) facility and an Intermediate Driver Facility (LDF) are required to develop the optimum features of an IFE heavy ion driver. Fusion Power Technology and Target Systems Technology development will require smaller experimental facilities that are ye: to be identified.

The Engineering Test Facility (ETF) will be the first facility to integrate all the major subsystems required for an inertial fusion power plant including the driver, target production and injection systems, blanket, chamber, and tritium systems. It will demonstrate the technical feasibility of IFE. A Demonstration Power Plant (DPP) would follow that would actually produce electricity. An upgradable driver would be used for the IDF, ETF, and DPP, and all of these facilities would be at the same site saving construction time and cost.

Before the ETF is built, four avenues of development concerned with target physics, driver technology, fusion power technology, and target systems technology will have produced positive results. A fusion power technology program (first walls and blankets, chamber dynamics, shielding, radiation confinement, chamber/driver interface, tritium recovery, etc.) and a target systems technology program (automated target production, target transport, target injection and tracking, beam steering, etc.) are needed to demonstrated certain key technologies needed to use fusion pulses to make steady power.

\section{POSSIBLE IFE EXPERIMENTS ON NIF}

Target Physics

The baseline target designs for the NIF are indirectly driven and this is, course reflected in the NIF design of the illumination system and the target chamber. (A means to convert the indirect drive scheme to an acceptable direct drive scheme, however, has been developed, that may allow up to $1.5 \mathrm{MJ}$ on blue light on a direct drive target. NIF advanced conceptual design activities will consider this option.] Although the workshop focussed on indirectly driven heavy-ion targets, there is, nevertheless, still substantial interest in direct drive targets and in laser and light-ion targets for IFE. For this reason and the possibility of a direct drive option on NIF, we consider these as well.

A significant number of the target physics issues for IFE will be addressed by the planned experiments on the NIF for ignition and defense sciences. These include optimization of target yield and gain, studies of capsule implosion characteristics, and studies of capsule ignition and burn physics. In parallel with this effort, there must be development and benchmarking of theoretical models and simulation codes needed for the understanding of target physics for IFE. In fact, the benchmarking of ICF computer codes in a regime or parameter space close to that of IFE may be one of the most significant contributions of the NIF for IFE. Thus, the already planned NIF experiments, by themselves, will greatly benefit IFE. Beyond these, the NIF should, however, perform certain additional experiments of importance to IFE that may not necessarily be part of current planning. Completely addressing IFE ion target issues on NIF will rely on the design of and experimentation with ion-like laser targets, such as the ones shown in Figure 1.

Table 1. List of IFE issues that will not necessarily be addressed by NIF core programs. An ' $X$ ' indicates issues that the NIF can resolve [assuming no direct drive capability].

\begin{tabular}{|l|c|c|c|c|}
\cline { 2 - 5 } \multicolumn{1}{c|}{} & \multicolumn{2}{c|}{ IONS } & \multicolumn{2}{c|}{ LASERS } \\
\cline { 2 - 5 } \multicolumn{1}{c|}{} & Indirect & Direct & Indirect & Direct \\
\hline Usability of a variety of pulse shapes & $X$ & $X$ & $X$ & $X$ \\
\hline $\begin{array}{l}\text { Radiation flow, illumination geometry and } \\
\text { internal pulse shaping }\end{array}$ & $\mathrm{X}$ & $\mathrm{NA}$ & $\mathrm{X}$ & $\mathrm{NA}$ \\
\hline $\begin{array}{l}\text { Sensitivity of capsules to radiation } \\
\text { asymmetry }\end{array}$ & $\mathrm{X}$ & $\mathrm{NA}$ & $\mathrm{X}$ & $\mathrm{NA}$ \\
\hline Materials issues (capsule, hohlraum, ablator) & $\mathrm{X}$ & $\mathrm{X}$ & $\mathrm{X}$ & $\mathrm{X}$ \\
\hline Fabrication surface finish and precision & $\mathrm{X}$ & $\mathrm{X}$ & $\mathrm{X}$ & $\mathrm{X}$ \\
\hline Cansule mounting and injection & $\mathrm{X}$ & & $\mathrm{X}$ & \\
\hline Power vs. energy tradeoffs & $\mathrm{X}$ & & $\mathrm{X}$ & $\mathrm{X}$ \\
\hline Output spectra and shielding & $\mathrm{X}$ & & $\mathrm{X}$ & $\mathrm{X}$ \\
\hline Reduced tritium & $\mathrm{X}$ & $\mathrm{X}$ & $\mathrm{X}$ & $\mathrm{X}$ \\
\hline Advanced targets & $\mathrm{X}$ & $\mathrm{X}$ & $\mathrm{X}$ & $\mathrm{X}$ \\
\hline
\end{tabular}


Table 1 lists the IFE issues thic. would be addressed by these experiments. An $\mathrm{X}$ indicates that the NIF can completely or almost completely resolve the issue. The table shows that the NIF can resolve most issues. We believe that the NIF, along with Omega Upgrade, PBFA II, and other facilities that exist or are under construction, will be able to address all of these issues. We believe that a completion of these experiments will indicate the readiness, from a target physics point of view, to proceed with an IFE engineering test facility.

Indirect-drive IFE target experiments require only minor changes, if any, to the NIF conceptual design. Furthermore, the target diagnostics and codes developed for the core program are directly applicable to IFE targets. It would be useful to conduct experiments where uniform illumination of a target could be obtained using only a fraction (e.g., 1/4 or 3/4) of the beams. It is noteworthy that each beamlet of the NIF is independent of the others in terms of spectral and temporal characteristics, such that this type of experiment is possible.

\section{Chamber Dynamics}

Many of the basic issues of IFE established from past fusion power plant conceptual designs and projected future options that relate to target chamber dynamics can be tested in NIF. The four basic categories of issues are (1) Target Response, (2) Material Response, (3) Gas Dynamics, and (4) Miscellaneous.
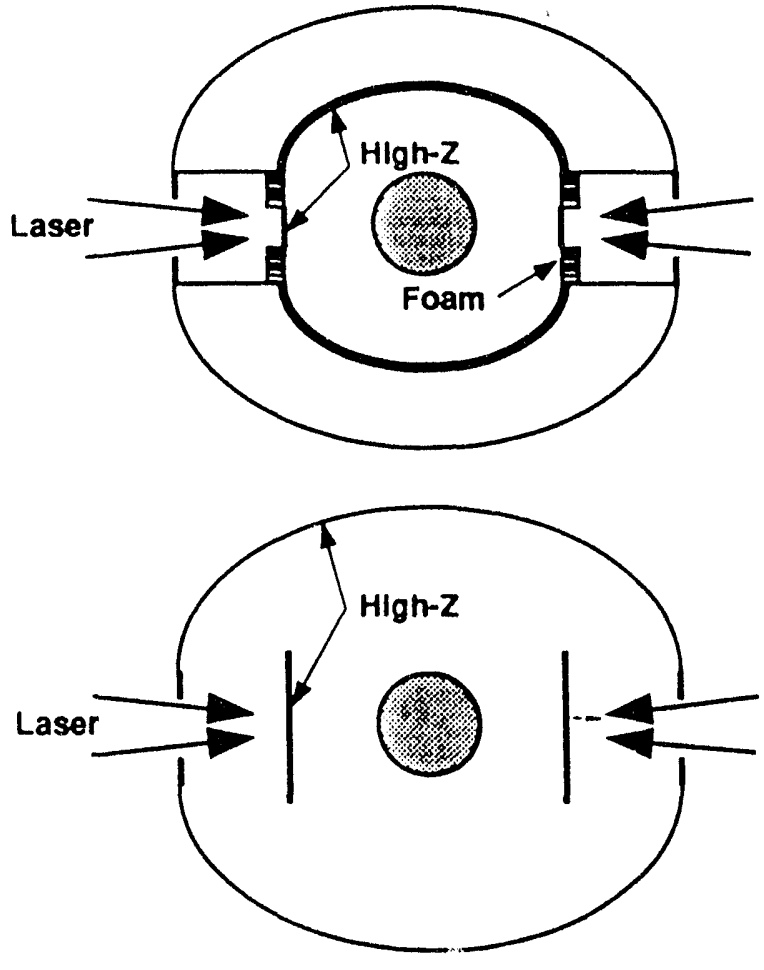

40-000504-25ento :

Fig. 1. Many IFE ion target issues can be addressed or resolved using ion-like laser targets.

Table 2. Materials Response Experiments on the NIF

\begin{tabular}{|c|c|c|c|c|c|c|}
\hline $\begin{array}{c}\text { Issues } \\
\text { Addressed }\end{array}$ & Experiment & Purpose & $\begin{array}{c}\text { Ignition } \\
\text { Required? }\end{array}$ & $\begin{array}{c}\text { Special } \\
\text { Diagnostics } \\
\text { Required }\end{array}$ & $\begin{array}{l}\text { Use 2nd } \\
\text { Chamber? }\end{array}$ & $\begin{array}{c}\text { NIF } \\
\text { Modifications }\end{array}$ \\
\hline Ablation & $\begin{array}{l}\text { Ablation } \\
\text { Issues }\end{array}$ & $\begin{array}{l}\text { Benchmark } \\
\text { ablation in } \\
\text { codes }\end{array}$ & Desired & $\begin{array}{l}\text { Pressure } \\
\text { transducers* } \\
\text { and mass } \\
\text { spectrometer }\end{array}$ & Yes & $\begin{array}{l}\text { None } \\
\text { (extra material } \\
\text { near target) }\end{array}$ \\
\hline $\begin{array}{l}\text { Erosion } \\
\text { (ablation, } \\
\text { melting, } \\
\text { surface } \\
\text { chemistry, } \\
\text { cumulative } \\
\text { damage) } \\
\end{array}$ & $\begin{array}{l}\text { Response of } \\
\text { Materials }\end{array}$ & $\begin{array}{l}\text { Measure } \\
\text { response of } \\
\text { suríace } \\
\text { material }\end{array}$ & Desired & None & Yes & $\begin{array}{l}\text { None } \\
\text { (vapors } \\
\text { condense; some } \\
\text { experiments } \\
\text { place materials } \\
\text { near target) }\end{array}$ \\
\hline $\begin{array}{l}\text { Isochoric } \\
\text { heating, } \\
\text { cavitation, } \\
\text { splash of } \\
\text { liquids } \\
\end{array}$ & $\begin{array}{l}\text { Liquid } \\
\text { Responses }\end{array}$ & $\begin{array}{l}\text { Study } \\
\text { isochoric } \\
\text { heating, } \\
\text { fluid } \\
\text { mechanics } \\
\end{array}$ & Yes & $\begin{array}{l}\text { Pressure } \\
\text { transducers } \\
\text { and strain } \\
\text { gauges }\end{array}$ & No & $\begin{array}{l}\text { Prepare for } \\
\text { liquid metals, } \\
\text { Si oils, etc. \& } \\
\text { graphite placed } \\
\text { near target } \\
\end{array}$ \\
\hline $\begin{array}{l}\text { Ablation } \\
\text { impulse, } \\
\text { pressure } \\
\text { loading, } \\
\text { stress } \\
\text { parameters }\end{array}$ & $\begin{array}{l}\text { Wall } \\
\text { Stresses }\end{array}$ & $\begin{array}{l}\text { Benchmark } \\
\text { stress codes }\end{array}$ & Yes & $\begin{array}{l}\text { Pressure } \\
\text { transducers* }\end{array}$ & No & $\begin{array}{l}\text { None } \\
\text { (vapor } \\
\text { condensation) }\end{array}$ \\
\hline
\end{tabular}

*Fast-response and high-sensitivity 
The Target Response category covers issues related to the characteristics of IFE target emissions in radiation and debris. Material response covers issues of radiation effects (including debris) at the first surface, structural wall, and blanket. Gas dynamics includes issues of chamber clearing, condensation, and beam propagation. The Miscellaneous category includes such issues as multiple-pulse radiation effects.

The experiments needed to address each of these issues are summarized in Table 2. Although preparatory experiments on Nova and other facilities are key for such aspects as assisting in developing predictive capabilities for chamber dynamics, NIF experiments [20 MJ] at $1-\mathrm{m}$ stand-off [ $48 \mathrm{~J} / \mathrm{cm}^{2}$ ] will mimic IFE [350 MJ] radiation fluences $\left[35 \mathrm{~J} / \mathrm{cm}^{2}\right]$ at $4-\mathrm{m}$. There are also several experiments that could be performed using laser energies of $100.400 \mathrm{~kJ}$. A NIF operational issue may the diagnosing and handling of liquids used in neutron isochoric heating experiments.

Ablation experiments considered would include the potential to use non-ignition sources [such as disks, or an array of disks]. In these experiments, perhaps onequarter of the NIF beams would each create a debris and $x$-ray source on each of four disks, separated in time enough that the time-dependent effects of the $x$-ray, debris, and ablated material from a single, large, close-in witness plate could be measured and compared to code predictions.

The activities required for getting ready to conduct IFE experiments on NIF include development of new diagnostics, use of Nova, use of ion-beam facilities, consideration of a second smaller NIF chamber, and code development.

New Diagnostics - There is a need for devices to measure the ion velocities (energies), species, and flux originating from target source debris. Also, there is a need for modest extensions of existing instrumentation in experiments related to gas dynamics and condensation phenomena. Moreover, there is a need for diagnostic development to adequately diagnose the gas/plasma conditions in potential beam propagation scenarios.

In addition to specific diagnostics, there is a general need for diagnostic protection against electromagnetic interference, especially from the high yield environment arising from gamma-induced EMP. Here, the IFE community can benefit from the NWET community, which has already attempted measurements in high radiation environments.

Use of Nova - Experiments should be performed on Nova to further characterize emitted $x$-ray and debris characteristics (including anisotropy) from target foils made of materials considered for IFE targets. Experiments on $x$-ray responses of first surface ablation, erosion, and some other surface effects-such as cumulative $x$-ray and debris damage and multiple-shot debris effects, should also be performed on Nova. Additionally, preparatory experiments should be performed to examine $x$-ray and debris effects on ionbeam final focus magnet materials.

Use of Ion-Beam Facilities - Experiments on ion-beam facilities are needed to benchmark codes for ion-beam transport losses that depend on gas pressure and transport conditions that will be present in NIF.

Development of a Second Smaller NIF Chamber - A smaller chamber may be cost effective for gas dynamics and condensation experiments, where only a few hundred kilojoules of laser energy is needed. The anticipated heavier debris-shield contamination could be tolerated and be spared the activation associated with the main NIF chamber. Work could be done on $x$-ray responses of first surface ablation, erosion, and multipleshot surface effects such as cumulative $x$-ray and debris damage, and cumulative heating effects. Partial simulations of a multiple-shot environment for gas dynamics could be studied by having at least two debris sources (bohlraum and target inserter, with other possible inserters). Further preparatory experiments could be performed on the smaller NIF chamber to investigate $x$ ray and debris effects on ion-beam optics materials, and on gas-fill pressure.

Code Development - Although there are many useful codes for estimating NIF behavior, many of these will require additional physics or modifications to meet IFE needs. There are three classes of codes that require development: (1) multi-phase (solid, melt, vapor) hydrodynamic, (2) gas hydrodynamic including condensation and some chemical effects, and (3) ionbeam codes.

\section{Fusion Power Technology}

Fusion power technology (FPT) in an IFE power plant includes components whose primary functions are energy conversion, tritium production and processing and radiation shielding. These components include a) wall protection and first wall, b) blanket, c) vacuum vessel, d) shield, e)tritium processing systems. Also relevant to FPT are remote maintenance systems and those elements of targets and drivers that provide either the source term and/or their performance is significantly affected by the radiation environment.

The dominant issues for FPT in IFE power plants concern the nuclear and material performance of components so as to achieve economic competitiveness 
and to realize safety and environmental advaritages. NIF will provide valuable information to IFE in two ways:

i) data from performance and operation of the basic device

ii) data from specially designed experiments

Particularly attractive features of NIF relevant to FPT are: A) Prototypical size and configuration, and B) Prototypical radiation field (neutrons, $x$-rays, debris) spectra and intensity per shot. For example, the NIF $[20$ $\mathrm{MJ}]$ neutron fluence at $1-\mathrm{m}\left[5.7 \times 10^{13}\right]$ is close to that for an IFE target [350 MI] at 40-m [6.2 $\left.\times 10^{13}\right]$. These features allow the possibility of conducting a range of valuable FPT-related experiments on NIF. The most important limitation of NIF for these FPT experiments is the low repetition rate. The planned repetition rate in NIF is too low to produce time-averaged relevant bulk nuclear heating and reactions.

Analysis of FPT issues and the range of possible experiments on NIF suggests that the most important contributions of NIF to FPT development for IFE are the following: 1) Achieving ignition; 2) System Integration - design, construction, and operation of the NIF will provide important information on the interactions among many important IFE subsystems, including FPT components; 3) Demonstration of viability of first-wall protection schemes; 4) Obtaining data on dose rate effects on radiation damage in materials; 5) Obtaining data relevant to tritium self sufficiency in IFE power plants; data includes a) tritium burnup fraction in target, b) some tritium inventory and flow rate parameters, and c) data on achievable tritium breeding rate; 6 ) Neutronics data on radioactivity, nuclear heating and radiation shielding.

Efforts and deliberations by the workshop participants suggested specific FPT experiments on NIF that appear to be both viable and useful. Future effort will need, of course, to address the details of such experiments and their impact on NIF design and operation. Some specific examples of NIF IFE experiments addressing a number of FPT-related issues are summarized.

Material Damage - NIF (and IFE) provides a very high dose rate in each shot that can be equivalent to about 10 to $1000 \mathrm{dpa} / \mathrm{s}$. [An IFE power plant experiences its entire annual neutron damage during only -10 seconds of actual irradiation time]. However, the limited number of NIF yield shots restricts the dose to a maximum of about $10^{-4}$ dpa in one year. Therefore, NIF cannot produce a design data base for IFE in metal alloys and composites (e.g. swelling, creep, embrittlement, Young's modulus, and thermal conductivity). However, NIF will be useful for basic physics of radiation effects in materials. Examples include: a) cascades (morphology, size, fraction of free and clustered defects, impurities), b) microstructural evaluation, c) electrical properties, d) optical properties (fiber optics, coatings), and e) molecular cross linking.

The incentive to produce low activation hazard structural materials for IFE also creates a dilemma: while the neutron activation characteristics may be fairly well understood, their mechanical properties under IFE conditions are generally unknown. The impact on the mechanical properties of materials compared to continuous irradiation (such $\mathrm{a} i$ in MFE) is not known. In addition, this short-pulse neutron effect must be understood in conjunction wih other effects such as $\mathrm{H}$, $\mathrm{He}$, and transmutation production, high-cycle fatigue, and thermal cycling, all at in-reactor temperatures.

In some low activation materials like $\mathrm{SiC}$, we predict that for IFE a large number of damage sites are produced in each pulse. Interstitials from one damage site combine with the vacancies created not only at that site, but also from adjoining or nearby sites, such that there is an increased rate of recombination compared to the steady state situation. Interstitials that do not find sinks in vacancies create clusters together, increasing clustering over the steady state example. Increased recombination tends to reduce void swelling while increased clusters tends to increase embrittlement.

A predictive capability that calculates material responses to IFE irradiation would be a powerful IFE design tool. A candidate for part of this capability is a technique called Molecular Dynamic Simulation [MDS]. This is a deterministic approach to predicting damage. It calculates responses at an atomic level by quantifying the response of a three-dimensional array of atoms to knockon atoms that impinge on the matrix from a range of angles and with a range of energies as a result of an incident neutron flux. Potentially, MDS capabilities may include predicting for a material the number of vacancies and interstitials that will result from neutron irradiation, as well as the cluster fraction of defects, atomic mixing and solute precipitation, and predict phase transformations. Its accuracy is dependent on the accurate modeling of interatomic potentials.

An overall material property predictive capability would use the results of MDS predictions along with a Monte Carlo defect annealing treatment, couple this 'source term' to finite element codes, and then predict the changes in bulk mechanical properties such as ultimate strength, Young's modulus, and fatigue limits. Data to benchmark MDS is essential if it is to be used as part of such a predictive capability. NIF can provide a source of relevant data for this purpose.

On NIF, neutrons will be produced two ways: from exploding pusher (directly driven) experiments that frequently are used to calibrate neutron diagnostics, and from indirect drive targets, with ignition. (Neutrons will be produced from NIF non-ignition indirect drive shots as 
well, but the neutron yield of these, at best, will likely be about the same as the direct drive shots). With $1.8 \mathrm{MJ}$ laser energy and a larger exploding pusher target. NIF will produce $\sim 10^{15}$ neutrons. Samples to be exposed to this neutron fluence could potentially be placed within $1-2 \mathrm{~cm}$ of the target, provided shrapnel generation was tolerable. Such experiments would be possible as soon as the NIF laser is activated ( 2001$)$. A series of experiments could be conducted to produce neutron damage in very small, thin samples. The first samples chosen for exposure would be those that have been well characterized and most computationally scrutinized by $\mathrm{MDS}$, such as $\mathrm{Ag}$, $\mathrm{Cu}$, and $\mathrm{Fe}$. The damaged samples would be examined with electron microscropic techniques to determine such damage parameters as number, distribution, and sizes of defect clusters. These measurements would be compared to MDS predictions. As shown in Table 3, NIF would create more than enough damage sites to allow confident validation of MDS techniques.

Table 3. Materials damage research with NIF exploding pusher experiments. These NIF damage levels are easily observed with scanning electron microscope techniques.

\begin{tabular}{|c|c|c|c|c|}
\hline & $\begin{array}{c}<\mathrm{T}> \\
\left(\mathrm{E}>\mathrm{E}_{\mathrm{d}}\right) \\
(\mathrm{keV})\end{array}$ & $\begin{array}{c}\text { Oint } \\
\text { (barnd } \\
\text { neutron) }\end{array}$ & $\begin{array}{c}\text { Dispiacements } \\
\text { per atom } \\
\text { (dpa) } \\
\left(\times 10^{-9}\right)\end{array}$ & $\begin{array}{l}\text { Number of } \\
\text { NIF neutron } \\
\text { damage sites* }\end{array}$ \\
\hline $\mathbf{S I}$ & 500 & 1.8 & 4.8 & 180 \\
\hline $\mathrm{C}$ & 689 & $\mathrm{~T} .2$ & 0.8 & 270 \\
\hline SiC & 600 & 1.5 & 3.0 & 150 \\
\hline $\mathrm{Fe}$ & 228 & 2.5 & 4.6 & 425 \\
\hline $\mathrm{Cu}$ & $190^{\circ}$ & 2.85 & 4.7 & 500 \\
\hline $\mathrm{Ag}$ & 72 & 4.1 & 2.5 & 300 \\
\hline
\end{tabular}

* \# of damage sites $=\sigma_{\text {int }} \times \Phi \times V \times \rho ; \Phi=2 \times 10^{14}$ $\mathrm{n} / \mathrm{cm}^{2} ; \mathrm{V}=10 \mathrm{~mm}^{2} \times 2000 \AA=2 \times 10^{-11} \mathrm{~cm}^{3}$

Another are of importance to material behavior is thermomechanical effects. NIF is unique in that it provides IFE prototypical thermal surface loads by $x$-rays and debris, in the range of $10^{-1}$ to $10^{-3} \mathrm{~J} / \mathrm{cm}^{2}$. Therefore, a limited amount of information for design and code verification can be obtained for IFE. Examples include: a) mechanics of bonded structures (composite interphase interfaces, mirror coatings, protective coatings), b) materials evaporation/ablation response, c) surface damage (flaking, spalling, material loss, shrapnel, and d) thermo-elastic wave bulk damage (fatigue, fracture).

Wall Protection - A large number of wall protection concepts have been proposed for IFE power designs, covering a diverse range of concepts with different testing needs. There are many issues associated with wall protection. They can be classified in 3 main categories: 1) Blast effects on film protectant thickness and stability; 2) Film/substrate interactions due to blast impulse; and 3) Damage rates at dry spots on filmprotected surfaces. While many aspects of the issues above can be addressed in separate small-scale facilities, NIF will be a useful testbed for examining these issues.

Prior to performing tests in NIF, a large amount of R\&D will be needed to derive the maximum benefit from testing. Several types of development are needed, including:

- Diagnostics - Numerous diagnostics are being developed for NIF to diagnose the target responses and energy yields from the blast. A large number of "engineering" diagnostics will be required in order to obtain useful information from testing. Some examples of needed measurements include film shape, thickness and motion; surface temperature and density of vapor leaving surface; net impulse and deflection of panels; mechanical response in structure, cavity vapor temperature, pressure and composition, and aerosols. While many of these diagnostics are well-develpoped for conventional applications, special effort will be required to demonstrate their effectiveness in the NIF environment and/or develop new instruments which can survive the blast.

- Model Development - A number of very useful models currently exist; however, these tend to be simplified, often 1-D, approximations. Many of the key issues involve more complex phenomena resulting from nonuniformities or complex interactions. Further model development will be needed to interpret the results of tests and to provide validation of codes which are sophisticated enough to be useful for design purposes.

- Basic Properties - In some cases, measurements of basic physical and chemical properties dre needed in order to provide inputs to codes and to interpret the results of tests.

- Small-scale Experiments - A large fraction of the remaining issues for wall protection can be addressed in existing or new facilities which are cheaper or more useful than NIF. For example, basic film flow measurements are very important as a reference point for measurements in NIF which include the effects of the blast.

Radioactivity and Nuclear Heating - A number of important neutronics experiments relevant to IFE appear to be viable on NIF, particularly for radioactivity/decay heat, biological dose and nuclear heating. These experiments include: a) radioactivity measurements in sample of materials to measure both short and long half life isotopic activities, b) measurements of radioactivity from activated debris and shrapnels, c) measurement of biological dose outside the cavity and outside the building, d) measurements of nuclear heating rate in samples of materials using microcalorimeter techniques. These measurements serve the following purposes: a) examine effects of high dose 
rate on double or triple neutron-induced reactions and transmutations, h) verify calculational cods and nuclear data libraries, and c) provide experiniental data for licensing future facilities such as ETF. It should be noted that the average neutron fluence obtainable in NIF, when ignited, at $20 \mathrm{MJ}$ fusion energy at the first wall $(-5 \mathrm{~m}$ from target) is $-2 \times 10^{12} \mathrm{n} / \mathrm{cm}^{2}$ per shot. Measurements have been conducted successfully recently at the FNS facility in Japan and in TFTR with DT shots at comparable fluences.

For nuclear heating, the state of the art of present techniques is such that a temperature rise greater than $1 \mathrm{mK}$ can be measured. Such a temperature rise is obtainable in NIF at $\sim 0.2 \mathrm{~m}$ from the target with a few $\mathrm{MJ}$ fusion yield. Higher yields will improve the accuracy of the nuclear heating measurements. Other experimental requirements to measure nuclear heating in NIF include: a) support 5 to 10 calorimeters at symmetric locations, b) weight per probe is $-800 \mathrm{~g}, \mathrm{c}$ ) must protect against non neutron heating, d) must protect against physical damage, e) need to extract within 5 to 10 minutes after shot.

Tritium Self Sufficiency - NIF can make partial by important contributions to demonstrating tritium self sufficiency by: a) performing measurements related to the required tritium breeding ratio; these include measurements of the tritium fractional burnup in the target, and measurements on tritium flow rates and inventories wherever it is possible in the facility, and b) measurements of the potentially achievable tritium breeding ratio in prototypical blanket modules.

Badiation Shielding (Bulk and for Penetrations) - The leakage of neutrons out of the target chamber could cause significant activation and radiation damage in outof-chamber components of experimental, demonstration and ICF power plants that will follow the NIF. The two primary components to the leaking neutrons are: 1) Deep penetration through the chamber wall, blanket (when it exists) and shield, and 2) Streamlining of neutrons through the beam ports and other penetrations in the large chamber.

In certain IFE plant concepts (such as HYLIFEII), it may be possible to significantly reduce the fraction of fusion neutrons which leak through the beam ports by use of in-vessel placed liquid jets or solid pencil shaped objects attached to the target. This "neutron beam stopper" is to make use of two unique reatures of the IFE neutron sources: their small volume of origin $(\ll 1 \mathrm{~mm})$ and the fact that the beam aim point is separated from the small dimension neutron source point by about $10 \mathrm{~mm}$ (so that the neutrons streaming towards the beam port follow a different path than the in beam path. The NIF will provide the first opportunity to experimentally verify the feasibility of this concept.
The NIF will provide intense enough neutron pulses and representative geometries to enable performing benchmark experiments which are expected to resolve most of the shielding issues of importance for the design of $\mathrm{IFE}$ reactors which will follow the NIF.

Thermal - Mechanical Struclural Response - NIF can provide important information relevant to some of the thermomechanical structural response of the vacuum vessel and the in-vessel components. For the vacuum vessel, information can obtained to assess the effect of multi penetrations on the integral response of the vessel to a several - MJ point source of energy release under normal and off-normal conditions. Examples of information to be obtained include in-vessel strain rate, stress concentration, vibrational modes, displacements, and energy damping rate. Such information can be used to partialiy benchmark design codes for IFE.

Beliability and Remote Maintenance - Remote maintenance capabilities should be designed with NIF, as they were for JET. They should be practiced during routine operation to develop efficient procedures and to uncover flaws of hardware, software, and procedures. Component failure rate data should be collected on NIF components. An extensive component failure rate data base will be needed as a prerequisite for doing probability/risk assessments that are essential for estimating accident frequencies.

Safety - As we consider safety issues for an eventual IFE power source the overriding concern is protection of the workers, public, and environment, including the consequences of accidents, exposures to radioactivity or toxic materials due to routine operations, and waste products. Specific issues include tritium and activation product inventories and gamma shielding to reduce doses to personnel.

NIF operation can provide useful data on routine tritium emissions, on tritium inventories in reactor components, and on the effects of neutron steaming on personnel doses. We can look for the production of mixed hazardous/radioactive waste during NIF operation, and devise strategies to cope with it or to avoid its generation. We need to verify predictions of activated materials produced from target materials, structural materials, or other components unique to IFE. For example, we can devise strategies for dealing with potential boron toxicity.

Performing the FPT experiments identified earlier on NIF requires three important activities: more detailed evaluation of experiments, efforts to gather and interpret relevant information generated in the magnetic fusion program, and conducting $R \& D$ specific to the proposed IFE experiments. 


\section{Target Systems}

Target Systems was defined broadly to include target fabrication (including capsule production, hohlraum production, target assembly, characterization, fill, and layeriıg), target materials and configuration selection, target transport from the target factory to the reaction chamber, and target insertion, tracking, and protection inside the reaction chamber. We have separated these into two broad areas: target fabrication and target transport. We discuss below for each of these areas, the issues that must be resolved in order to successfully develop an inertial fusion energy power plant, and the experiments that could be done in the NIF to help resolve these issues.

Eabrication Issues with IFE Targets - The targets that fuel an inertial fusion power plant based upon the indirect drive approach will be similar to the ignition and high gain targets developed for the NIF. The IFE fuel capsules, however, will be two-to-three times larger in diameter since capsule size scales according to the cuberoot of the absorbed energy . For a laser driver, hohlraums will scale similarly. Heavy ion drivers will require substantially different hohlraums and $x$-ray converters. As with NIF high gain targets, IFE targets will be cryogenic. The major issues associated with developing these targets, broadiy stated, are: 1) assuring the target component quality specifications as sizes increase and fabrication techniques change; 2) assuring a fast enough fuel fill rate to be able to maintain the plant tritium inventory at acceptable levels; and 3) developing fabrication and inspection techniques that produce high quality, economically viable targets. A fourth issue, dealt with in the following section on target transport, is providing taigets that can withstand the accelerations attending chamber injection, and can withstand the chamber environment once injected.

Table 4 lists more fine-grained issues that must ultimately be addressed to produce and use IFE targets, together with an assessment of the importance of the NIF in developing solutions. In summary, most IFE target requirements can be developed "off line". Those that require full scaling to IFE sizes, such as capsule surface morphology, cannot be completely tested to ignition on the NIF. Those that do not require such scaling, such as changes in capsule material or target assembly techniques, should be tested on the NIF. The NIF would be a unique test-bed, since the relevant test of success is ignition.

\begin{tabular}{|c|c|c|}
\hline Table 4. Target Fabricatio & NIF Usefulness* & NIF Uniqueness** \\
\hline $\begin{array}{l}\text { Low-cost mass-production techniques for capsules and } \\
\text { their effect on quality, materials choice and gain }\end{array}$ & 2 & 3 \\
\hline Low cost mass production techniques for laser driver hohlraums & 2 & 3 \\
\hline The effect of cryogenic layer quality on gain & 2 & 3 \\
\hline Automated cryogenic assembly techniques & 3 & 3 \\
\hline Fast fill techniques for low tritium inventory & 2 & 3 \\
\hline High-throughput quality inspection techniques & 2 & 3 \\
\hline
\end{tabular}

* Usefulness: 3 = Complete resolution, 2 = Partial resolution, $1=$ Useful information, $0=$ No use

** Uniqueness: 3 = NIF unique and required, 2 = NIF not unique but could be used, 1 = Issue addressed better or cheaper in new facility, $0=$ Issues adressed better or cheaper in existing facility

\begin{tabular}{|c|c|c|}
\hline Table 5. Target Transport Issues & NIF Usefulness* & NIF Uniqueness** \\
\hline Injection techniques for high rep-rate cryogenic operation & $\mathbf{0}$ & 1 \\
\hline Time and space accuracy and sensing & $\mathbf{0}$ & 1 \\
\hline Integration & 2 & 1.2 \\
\hline Target survival under acceleration & 2 & 3 \\
\hline Thermal protection and temperature control & 2 & 2 \\
\hline Chamber environment effects on trajectory & $1-2$ & 3 \\
\hline Demonstration of high rep rate operation & 2 & 3 \\
\hline
\end{tabular}

* Usefulness: $3=$ Complete resolution, $2=$ Partial resolution, $1=$ Useful information, $0=$ No use

* Uniqueness: 3 = NIF unique and required, 2 = NIF not unique but could be used, 1 = Issue addressed better or cheaper in new facility, $0=$ Issues adressed better or cheaper in existing facility 
Target Transpor Issues - Under the category of target transport, we include both transport from the target fabrication facility to the target injector and the injection of the target to the point of ignition. Completed targets will be stored in a cryogenic storage system prior to transport to the injector and must be kept at constant temperature throughout the entire transport and injection process. Even after the target leaves the injector and enters the chamber environment, the allowed temperature rise of the cryogenic fuel is very low, estimated to be less than $0.2 \mathrm{~K}$. Targets must also survive the acceleration process. The target transport issues for IFE are listed in Table 5. As indicated the NIF will be useful for addressing many of these issues.

Target Systems - Research and development needs for target systems are summarized in Table 6. Target fabrication and injection systems for IFE will require development. Some of the target fabrication issues must be faced in order to field ignition targets on NIF and will require continuation and expansion of current target development activities. The testing proposed in NIF of IFE-relevant targets will require that those targets first be developed. Relatively little has been done in that area to date. We recommend a program of target design and fabrication $R \& D$ to have prototypic IFE targets ready for testing on NIF. This testing will come after the NIF primary mission of ignition has been achieved, that is, about 5 years after the startup of the NIF.

Cryogenic ignition experiments on NIF will require cryogenic target transport systems. Development of these systems will benefit greatly from work on similar systems being developed for OMEGA Upgrade. IFE will require sophisticated target injection and tracking systems that have yet to be seriously studied. IFE target experiments on NIF will require a portion of the development needed on these systems to be done. We recommend that IFE tracking and pointing studies be done to define the systems that could be tested on NIF, followed by development of the required hardware for these experiments. These experiments would logically follow the static tests of IFE prototype targets described above.

Table 6. Target Systems R\&D Needs

\begin{tabular}{|c|c|c|c|c|}
\hline Development Item & $\begin{array}{l}\text { Needed for } \\
\text { NIF }\end{array}$ & $\begin{array}{l}\text { Needed for } \\
\text { NIF IFE } \\
\text { Experients }\end{array}$ & $\begin{array}{l}\text { Needed for } \\
\text { IFE }\end{array}$ & $\begin{array}{l}\text { Current } \\
\text { R\&D } \\
\text { Activity* }\end{array}$ \\
\hline \multicolumn{5}{|l|}{ Target Fabrication } \\
\hline \multicolumn{5}{|l|}{ Targets for Ignition } \\
\hline Ignition target design & $\bar{X}$ & & & A \\
\hline $1.3 \mathrm{~mm}$ capsules & $\mathrm{X}$ & $\bar{X}$ & $\bar{X}$ & $\bar{B}$ \\
\hline High pressure DT' fill and condense & $\bar{X}$ & $\bar{X}$ & $\bar{X}$ & $\bar{C}$ \\
\hline Cryogenic layering & $\bar{X}$ & $\bar{X}$ & $\bar{X}$ & $\bar{D}$ \\
\hline Cryogenic characterization & $X$ & $\bar{X}$ & $\mathrm{X}$ & $\mathrm{D}$ \\
\hline Cryogenic assembly & $\mathbf{X}$ & $\mathrm{X}$ & $\mathbf{X}$ & - \\
\hline \multicolumn{5}{|l|}{ Targets for IFE } \\
\hline IFE target design & & $\mathrm{X}$ & $\mathrm{X}$ & - \\
\hline IFE target fabrication & & $\mathrm{X}$ & $\mathrm{X}$ & - \\
\hline Cost-effective fabrication & & & $\mathrm{X}$ & - \\
\hline \multicolumn{5}{|l|}{ Target Transport } \\
\hline \multicolumn{5}{|l|}{ Transport Systems } \\
\hline Transport to reaction chamber & $\mathrm{X}$ & $\mathrm{X}$ & $\mathrm{X}$ & C \\
\hline High through-put transport & & & $\bar{X}$ & - \\
\hline \multicolumn{5}{|l|}{ Injection and Tracking } \\
\hline Stationary mounting system & $\mathbf{X}$ & $\mathrm{X}$ & & $\mathrm{C}$ \\
\hline Free-fall injection & & $\mathrm{X}$ & & - \\
\hline High speed injection & & $\mathrm{X}$ & $\mathrm{X}$ & - \\
\hline High rep rate, rad-hardened injection & & & $\mathrm{X}$ & $=$ \\
\hline Target tracking & & $\mathrm{X}$ & $\mathrm{X}$ & - \\
\hline Hardened target tracking & & & $\mathrm{X}$ & $=$ \\
\hline
\end{tabular}

*A-NiF Design Activity; B-Target Fabrication Development Activity; C-OMEGA Upgrade Design;

D-National Cryogenic Target R\&D Program 


\section{THE VALUE OF NIF FOR IFE}

The role of the NIF can uniquely cover a large and essential portion of needed IFE development in the areas of IFE target physics and design/performance optimization, IFE fusion chamber dynamics and first wall response, IFE fusion power technology, materials science and safety, and for final precision/performance tests of mass-fabricated IFE targets and high-repetition target injection systems.

The general focus of the proposed uses of NIF for IFE development is aimed at understanding the basic underlying target and target chamber phenomenology, physics, and materials science reeded to design the ETF, an IFE development facility to follow the NIF, and to guide the selection of IFE technologies needed for future IFE power plents. Accordingly, the purpose of the NIF experiments are to benchmark and improve the computational tools to be used for future IFE system designs, instead of trying to pick winners and losers of IFE technology options from empirical tests. It is therefore sufficient for these purposes, as we found, that NIF provides target chamber environment conditions close to, but not necessarily the same as, conditions expected in specific IFE power plant concepts. The use of the NIF to establish predictive design capabilities for IFE is the key to cost-effective IFE development. The nation cannot afford to develop IFE concepts empirically, in Darwinian-evolution fashion.

Nearly all of the potential IFE-development experiments suggested for NIF can be performed within the present NIF laser system design capabilities and functional requirements, and will, with a few exceptions noted below, not require expensive modifications to the NIF target chamber. However, the scope, number and scale of identified NIF experimental campaigns for IFE implies (a) significant need for preparatory IFE developments concurrent with NIF construction and initial operation, to be ready to field some of the more important IFE experiments on NIF once ignition is achieved, and (b) a very significant additional number (2000 to 3000) of desired NIF shots for IFE-specific experiments with and without yield, including possible "piggy-backing", beyond those needed to produce the first ignition demonstration in the NIF (e.g., after year 2004). These NIF workshop findings need to be included in the overall national IFE development plans and in the planning for $\mathrm{NIF}$ operations over 10 years after construction. These plans need to be coordinated with the output from the other NIF workshops for weapons physics, nuclear weapons effects simulation, and basic high-energy density science.

Developments are needed for NIF-IFE experiments. Diagnostics are needed for post-bang-time characterization of target emissions and distribution within the target chamber. These include fast, spatially resolved pressure transducers, neutron activation and heating microcalorimeters, ion mass spectrometers, and visible/uv/x-ray backlighters positioned to view target debris and wall ablation, including droplet motion, on relevant spatial scales. Many of these new diagnostics, and diagnostic techniques for specific IFE experiments, would benefit from initial development tests in Nova before use in NIF.

Many IFE experiments will involve various amounts of liquid and solid test samples which will condense out on the NIF chamber walls and optics windows. Compatibility tests are needed to design the NIF Vacuum Recovery System (VRS) to cope with the introduction of these condensates, and to guide the selection of compatible liquid and solid surrogates to model the dynamics of IFE material responses.

A large fraction of the NIF shots for IFE experiments do not need full NIF laser energy or fusion yield, at least for most of their test sequence up to a final full-yield NIF test. Simple foil targets can provide characteristic soft-xray and debris spectra, at minimum relevant fluences of $>100 \mathrm{~J} / \mathrm{cm}^{2}$ ove : $>1900 \mathrm{~cm}^{2}$ samples for relevant spatial and time scales for IFE ablation studies, requiring minimum lace. energies of a few hundred $\mathrm{kJ}$. Also, some IFE material samples may not be compatible with even a modified NIF VRS cleanup system for the main NIF chamber. For these reasons, a smaller separate target chamber for non-yield IFE experiments at 100 to $400 \mathrm{~kJ} \mathrm{3w}$ laser energy, with a simple single-sided illumination geometry, is highly desirable.

To support the credibility of high-rep-rate IFE for an ETF decision in 2005, it is highly desirable if NIF can demonstrate multi-shot target precision/symmetry reproducibility in a high-rep-rate target chamber environment, by shooting a sequence of at least two or perhaps four IFE model targets injected on the fly $200 \mathrm{~ms}$ apart, with reproducible laser illumination symmetry, in the main NIF target chamber. If this NIF test is feasible (currently being examined), then appropriate prior development of the multi-shot IFE model target fabrication, tracking, and insertion systems need to start, beginning in about 1998, to be ready to perform this test, if required, for an ETF decision shortly after first ignition is achieved $(\sim 2004-2005)$.

\section{CONCLUSIONS}

Many experiments can be done on NIF to address some of the critical issues of IFE fusion power and target systems technologies. Using the output of ignited targets, NIF experiments will be able to characterize radiation, shock, and debris effects on various first wall candidates and on driver/reactor interface systems providing the data necessary to design multiple pulse and high rep-rate experiments for the ITF. 
NIF experiments will be essential for calibratinging and improving the predictive capabilities of $x$-ray, debris and neutron emissions and their effects. NIF experiments can study the target manufacturing tolerances required for mass production and the positioning requirements of the injection, tracking and beam pointing systems. NIF will be not only a target physics facility, but an important experimental facility to support a broad range of research on the IFE development path.

\section{ACKNOWLEDGMENTS}

This work was performed under the auspices of the U.S. Department of Energy by Lawrence Livermore National Laboratory under Contract W-7405-Eng-48. 

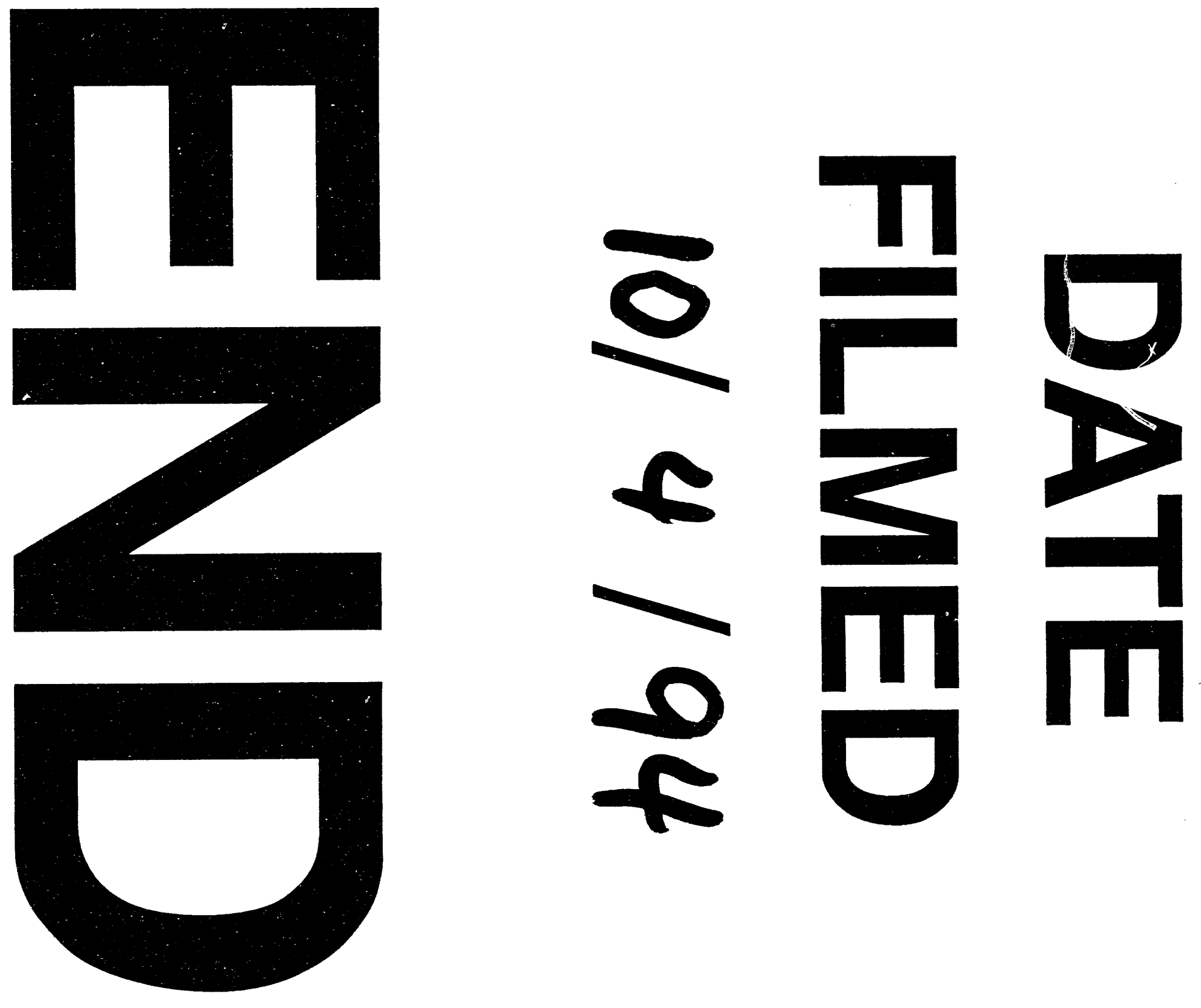
